\title{
Prevalence of anemia and associations between neonatal iron status, hepcidin, and maternal iron status among neonates born to pregnant adolescents
}

\author{
Sunmin Lee ${ }^{1}$, Ronnie Guillet ${ }^{2}$, Elizabeth M. Cooper ${ }^{3}$, Mark Westerman ${ }^{4}$, Mark Orlando ${ }^{5}$, Tera Kent ${ }^{1}$, Eva Pressman ${ }^{3}$ \\ and Kimberly O. O'Brien'
}

\begin{abstract}
BACKGROUND: Little is known about anemia and iron status in US newborns because screening for anemia is typically not undertaken until 1 y of age. This study was undertaken to characterize and identify determinants of iron status in newborns born to pregnant adolescents.

METHODS: Pregnant adolescents ( $\leq 18 y, n=193$ ) were followed from $\geq 12$ wk gestation until delivery. Hemoglobin, ferritin, soluble transferrin receptor, serum iron, hepcidin, erythropoietin (EPO), IL-6, and C-reactive protein were assessed in maternal and cord blood.
\end{abstract}

RESULTS: At birth, $21 \%$ of the neonates were anemic $(\mathrm{Hb}<$ $13.0 \mathrm{~g} / \mathrm{dl}$ ) and $25 \%$ had low iron stores (ferritin $<76 \mu \mathrm{g} / \mathrm{l}$ ). Cord serum ferritin concentrations were not significantly associated with gestational age (GA) at birth across the range of 37-42 wk. Neonates born to mothers with ferritin $<12 \mu \mathrm{g} / \mathrm{l}$ had significantly lower ferritin $(P=0.003)$ compared to their counterparts. Hepcidin and IL-6 were significantly $(P<0.05)$ higher in neonates born to mothers with longer durations of active labor.

CONCLUSION: Given the importance of the iron stores at birth on maintenance of iron homeostasis over early infancy, additional screening of iron status at birth is warranted among those born to this high risk obstetric population.

$\mathbf{T}$ he iron endowment at birth helps support optimal growth and development throughout early infancy. Little attention has been focused on the assessment of iron status at birth because of the belief that sufficient iron will be accrued across gestation even in the face of mild-to-moderate maternal anemia (1). However, an increasing body of evidence indicates that iron stores may be compromised in newborns born to women with low iron stores (2). This is of concern given the growing literature on developmental programming that highlights the importance of iron acquisition in utero on long-term functional consequences (3), and animal data indicate that there are critical windows for the role of iron on fetal brain development (4). In spite of growing attention to the importance of optimal fetal iron accretion, US infants are not typically screened for anemia until $1 \mathrm{y}$ of age, and normative data on comprehensive indicators of neonatal iron status at birth are limited.

The majority of fetal body iron is obtained during the last trimester of pregnancy (5); therefore, neonates born preterm or early-term may be at risk of insufficient iron endowment. The definition of "term", has recently been refined to classify neonates as early (37-39wk gestation), full (39-41 wk gestation), late (41-42 wk gestation), or post-term ( $\geq 42 \mathrm{wk}$ gestation) (6). Early-term neonates are at higher risk of nonoptimal developmental outcomes compared to infants born at $39 \mathrm{wk}$ gestational age (GA) or later (7). At this time, little is known about iron status in healthy, term neonates born to pregnant adolescents and on relative changes in iron stores that can be accrued over the last 3-5 wk of gestation.

The fetus may be able to regulate placental iron trafficking via production of fetal hepcidin that is produced by the fetal liver early in gestation (8). Hepcidin is the master regulator of iron homeostasis, and the production of this hormone is known to be regulated by iron stores, inflammation, hypoxia, and erythropoietic activity (9). Despite its crucial role in regulation of iron homeostasis, currently, little is known about fetal hepcidin production and its regulatory function, and few normative hepcidin data are available in maternal-neonatal pairs at birth (10-12).

This study was undertaken to characterize iron status at birth in a group of healthy term neonates born to pregnant adolescents, a group at increased risk of maternal anemia and iron deficiency, and to explore the associations between neonatal iron status and hepcidin in relation to maternal iron status in a higher risk obstetric population.

\section{RESULTS}

The characteristics of the 193 term newborns are presented in Table 1. Although pregnant adolescents typically have higher risks of poor pregnancy outcomes when compared to adults (13), birth rates of early-term (21\%), full-term (59\%), and late/

\footnotetext{
Clinical Trial Registration: NCT01019902

'Division of Nutritional Sciences, Cornell University, Ithaca, New York; ${ }^{2}$ Department of Pediatrics, Neonatology, University of Rochester School of Medicine and Dentistry, Rochester, New York; ${ }^{3}$ Department of Obstetrics and Gynecology, University of Rochester School of Medicine and Dentistry, Rochester, New York; ${ }^{4}$ Intrinsic Life Sciences LLC, La Jolla, California; ${ }^{5}$ Department of Otolaryngology, University of Rochester School of Medicine and Dentistry, Rochester, New York. Correspondence: Kimberly O. O'Brien (koo4@cornell.edu)

Received 20 November 2014; accepted 15 July 2015; advance online publication 14 October 2015. doi:10.1038/pr.2015.183
} 
Table 1. Characteristics of the term newborns at birth $(n=193)$

\begin{tabular}{|c|c|c|}
\hline & $\begin{array}{c}\text { Subjects with } \\
\text { available data }(n)\end{array}$ & $\begin{array}{l}\text { Mean } \pm \text { SD } \\
\text { or } \%(n)\end{array}$ \\
\hline Gestational age (weeks) & 193 & $39.9 \pm 1.2$ \\
\hline Early term, $\%(n)^{\mathrm{a}}$ & & $21(41)$ \\
\hline Full term, $\%(n)^{\mathrm{a}}$ & & $59(113)$ \\
\hline Late term, $\%(n)^{\mathrm{a}}$ & & $19(37)$ \\
\hline Post-term, \% $(n)^{\mathrm{a}}$ & & $1(2)$ \\
\hline Mode of delivery & 191 & \\
\hline Vaginal delivery, $\%(n)$ & & $92(176)$ \\
\hline Cesarean section, \% (n) & & $8(15)$ \\
\hline Gender & 193 & \\
\hline Male, \% (n) & & $50(96)$ \\
\hline Female, $\%(n)$ & & $50(97)$ \\
\hline Birth weight (g) & 193 & $3270.1 \pm 439.1$ \\
\hline Head circumference $(\mathrm{cm})$ & 153 & $33.5 \pm 2.5$ \\
\hline Birth length (cm) & 182 & $51.1 \pm 2.6$ \\
\hline Apgar score (1 min) & 189 & $7.8 \pm 1.4$ \\
\hline Race & 193 & \\
\hline African-American, \% ( $n$ ) & & $70(136)$ \\
\hline Caucasian, \% (n) & & $30(57)$ \\
\hline Ethnicity & 193 & \\
\hline Hispanic, \% (n) & & $26(50)$ \\
\hline Non-Hispanic, \% (n) & & $74(143)$ \\
\hline
\end{tabular}

post-term neonates $(20 \%)$ in this cohort were not significantly different $(P=0.09)$ from the national birth rates of early(24.7\%), full- $(50.8 \%)$, or late/post-term neonates (14.6\%), respectively (14). The mean birth weight of these term neonates was $3,270 \pm 439 \mathrm{~g}$, which was significantly lower $(P<0.001)$ than that reported for term US singleton births $(3,389 \pm 466 \mathrm{~g})$ (15), but comparable to the mean birth weight of neonates born to adolescents $(3.25 \pm 0.02 \mathrm{~kg})(16)$. Small-for-GA was observed in $18 \%(n=34)$ of term newborns, which was significantly higher $(P=0.001)$ than the national rate $(10-11 \%)(17)$.

\section{Neonatal Anemia and Hemoglobin Concentrations}

Cord blood $\mathrm{Hb}$ concentrations and iron status indicators are presented as a function of GA grouping in Table 2. Two neonates were born post-term ( $42.1 \pm 0.1 \mathrm{wk}$ gestation); data from these two neonates were combined into the late-term grouping. The mean $\mathrm{Hb}$ concentration in term neonates $(n=113)$ was $14.4 \mathrm{~g} / \mathrm{dl}$ (95\% confidence interval (CI): 13.9, 14.9) and anemia was evident in $21 \%(n=24)$ of these neonates at birth. African-American neonates had significantly lower mean $\mathrm{Hb}$ concentrations compared to Caucasian neonates $(14.1 \mathrm{~g} / \mathrm{dl}$, (95\% CI: $13.6,14.6), n=84$ vs. $15.4 \mathrm{~g} / \mathrm{dl}$, (95\% CI: $14.3,16.5)$, $n=29, P=0.03)$; however, the prevalence of anemia did not differ significantly between the two racial groups $(23 \%$ in African-American neonates vs. $17 \%$ in Caucasian neonates, $P=0.54)$. Neonatal anemia was observed among $16 \%$ of term neonates born to mothers who self-reported use of prenatal supplements $\geq 2-5$ times/week compared to $33 \%$ of neonates born to mothers with who self-reported less frequent use of supplements $(P=0.04)$.

\section{Neonatal Iron Status in Term Neonates at Birth}

In term neonates $(n=181)$, the mean cord serum ferritin (SF) concentration was $114.4 \mu \mathrm{g} / \mathrm{l}$ (95\% CI: 102.5, 127.7), with $25 \%$ $(n=45)$ having cord SF $<76 \mu \mathrm{g} / \mathrm{l}$. SF concentrations were not significantly associated with GA at birth across the range of $37-42 \mathrm{wk}(P=0.69)$, nor were they associated with weight $(P=0.99)$, gender $(P=0.97)$, or race $(P=0.93)$. The percentage of term neonates with SF $<76 \mu \mathrm{g} / \mathrm{l}$ more than doubled in neonates born to mothers with dietary iron intakes less than the estimated average requirement $(23 \mathrm{mg} / \mathrm{d})(18)$, compared to those with iron intakes $\geq 23 \mathrm{mg} / \mathrm{d}$ ( $27 \mathrm{vs.} 11 \%, P=0.04$ ).

The mean concentration of cord soluble transferrin receptor (sTfR) was $7.6 \mathrm{mg} / \mathrm{l}$ (95\% CI: 7.2, 8.1), $n=183$, and cord sTfR was positively correlated with GA $(r=0.32, P<0.0001, n=183)$. A significantly $(P<0.05)$ higher concentration of cord sTfR $(9.0 \mathrm{mg} / \mathrm{dl})$ was observed in late/post-term newborns (95\% CI: $7.8,10.4), n=38$, when compared to early-term $(6.6 \mathrm{mg} / \mathrm{l},(95 \%$ CI: $6.0,7.2), n=39)$ or full-term neonates $(7.6 \mathrm{mg} / \mathrm{l},(95 \% \mathrm{CI}$ : $7.1,8.1), n=106)$. This finding was not significantly different if the sTfR data from the one post-term newborn in whom sTfR data was available was excluded from this analysis.

The mean concentration of cord erythropoietin (EPO) was $32.1 \mathrm{mIU} / \mathrm{ml}$ (95\% CI: 28.2, 36.2), $n=163$. Cord EPO was positively correlated with GA $(r=0.32, P<0.0001, n=163)$ and early-term newborns had a significantly $(P<0.05)$ lower EPO concentration (21.8 mIU/ml, (95\% CI: 17.3, 27.1), $n=32$ ) compared to full-term $(32.8 \mathrm{mIU} / \mathrm{ml},(95 \% \mathrm{CI}: 28.2,38.5)$, $n=97)$ and late/post-term neonates $(43.4 \mathrm{mIU} / \mathrm{ml},(95 \% \mathrm{CI}$ : $31.5,59.7), n=34)$.

The mean concentration of cord hepcidin was $92.8 \mathrm{ng} / \mathrm{ml}$ (95\% CI: 82.3, 105.6), $n=179$. Cord hepcidin was significantly positively associated with the total duration of labor $\left(R^{2}=0.07\right.$, $P<0.001, n=152)$, and with the duration of Stage $1\left(R^{2}=0.05\right.$, $P=0.005, n=152)$ and Stage 2 labor $\left(R^{2}=0.08, P<0.001\right.$, $n=153)$. The mean concentrations of IL- 6 was $9.4 \mathrm{pg} / \mathrm{ml}(95 \%$ CI: 7.2, 12.2), $n=156$, and similar to the hepcidin findings, cord IL-6 was significantly positively associated with the total duration of labor $\left(R^{2}=0.04, P=0.02, n=131\right)$, and with the duration of Stage 2 labor $\left(R^{2}=0.06, P=0.007, n=132\right)$.

\section{Correlations Between Neonatal Iron Status Indicators}

Table 3 presents correlations between cord $\mathrm{Hb}$ concentrations and indicators of iron status. Among term-neonates, cord $\mathrm{Hb}$ was significantly negatively associated with cord SF $\left(R^{2}=0.07\right.$, $P=0.006, n=109)$, and cord sTfR was significantly positively associated with cord EPO $\left(R^{2}=0.14, P<0.001, n=163\right)$. Cord hepcidin concentrations were significantly positively associated with cord SF $\left(R^{2}=0.18, P<0.001, n=178\right)$ and cord IL-6 $\left(R^{2}=0.09, P<0.001, n=155\right)$, and significantly negatively associated with cord EPO $\left(R^{2}=0.05, P=0.004, n=162\right)$ and cord $\operatorname{sTfR}\left(R^{2}=0.03, P=0.02, n=179\right)$. 
Table 2. Neonatal hemoglobin concentrations and indicators of iron status by gestational age groups ${ }^{\mathrm{a}}$

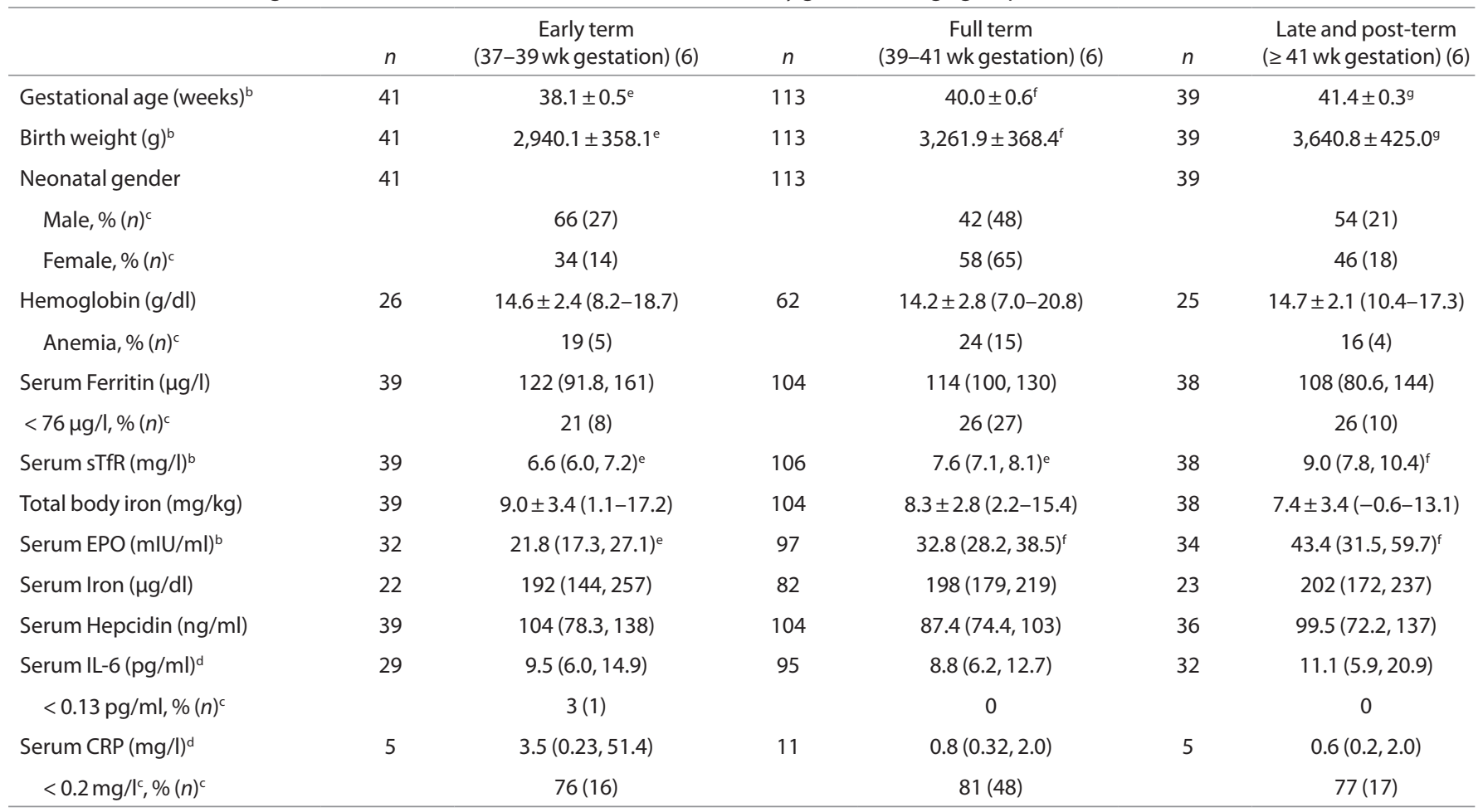

Cl, confidence interval; CRP, C-reactive protein; EPO, erythropoietin; IL-6, Interleukin-6; sTfR, soluble transferrin receptor.

aData are presented as the mean \pm SD (range) for hemoglobin and total body iron; geometric mean (95\% CI) for CRP, EPO, ferritin, hepcidin, IL-6, and serum iron. ${ }^{b}$ Values within a row that do not share a common superscript statistically differ. Gestational age, $P<0.0001$; birth weight, $P<0.0001$; serum sTfR, $P<0.05$; serum EPO, $P<0.05$. c No significant differences were observed in the number or percentage between gestational age groups. ${ }^{\text {Un }}$ Undetectable values were excluded from calculations. ${ }^{\text {ef, }} \mathrm{G}$ Group means without a common letter in a row differ, $P<0.05$.

Table 3. Correlations between gestational age, birth weight, and iron status indicators of term neonates

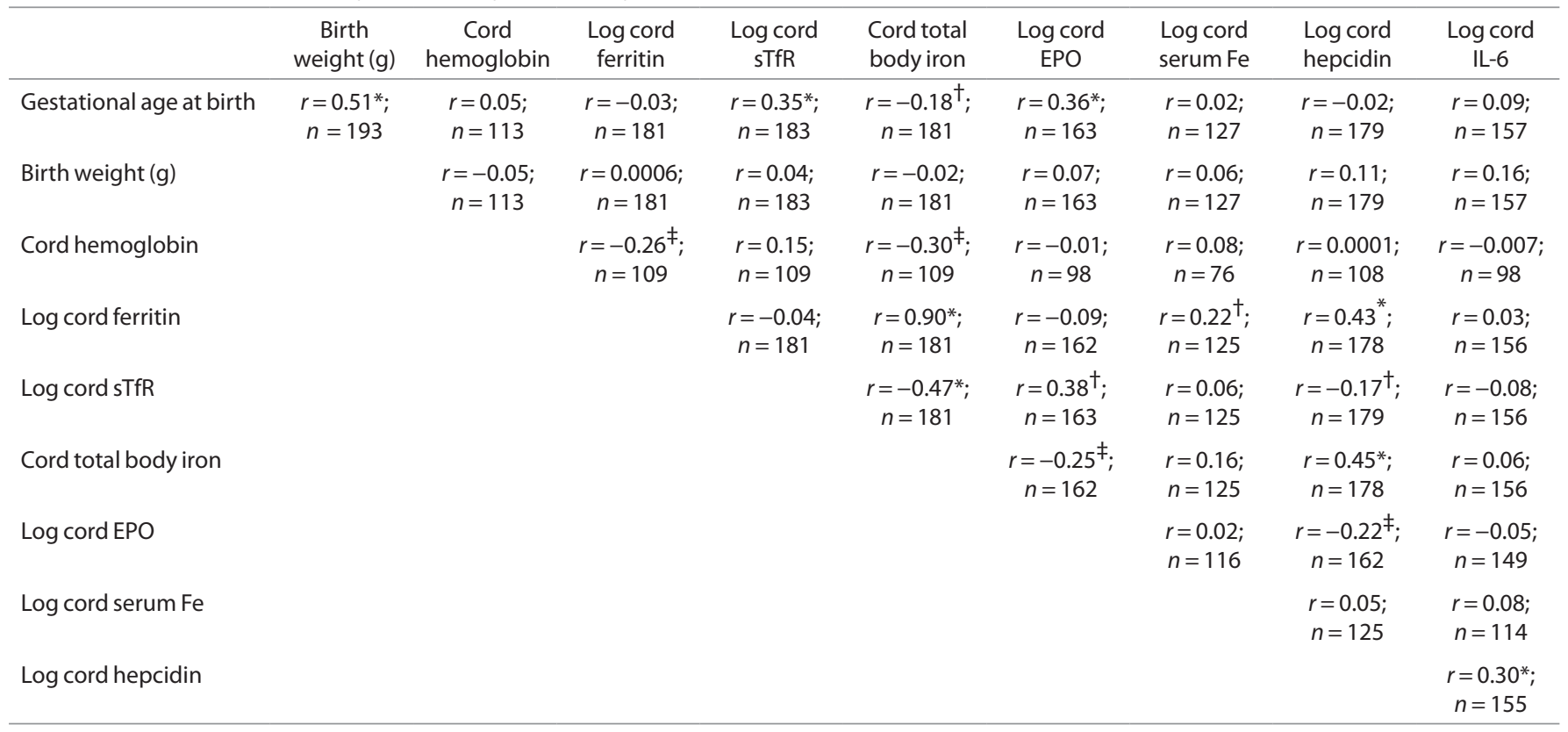

EPO, erythropoietin; Fe, iron; IL-6, interleukin-6; sTfR, soluble transferrin receptor. ${ }^{*} P<0.001 ;{ }^{+} P<0.05 ;{ }^{\ddagger} P<0.01$.

\section{Associations Between Neonatal Iron Status and Maternal Iron Status}

Table 4 presents the correlations between maternal and neonatal iron status indicators obtained at mid-gestation and at delivery. Cord SF concentrations were significantly positively associated with maternal SF at mid-gestation $\left(R^{2}=0.11, P<\right.$ $0.001, n=106)$. Neonates born to mothers with $\mathrm{SF}<12.0 \mu \mathrm{g} / \mathrm{l}$ at mid-gestation $(27.1 \pm 3.5 \mathrm{wk}$ gestation) had on average $34 \%$ 
Table 4. Correlations between maternal and neonatal iron status indicators at mid-gestation ( $26.1 \pm 3.5$ wk gestation) and at delivery $\left(39.9 \pm 1.2\right.$ wk gestation $^{\mathrm{a}}$

\begin{tabular}{|c|c|c|c|c|}
\hline & $N$ & Maternal mid-gestation & Cord blood & $r(P)$ \\
\hline Hemoglobin (g/dl) & 61 & $11.2 \pm 0.9(8.7-13.3)$ & $14.2 \pm 2.7(8.2-20.8)$ & $-0.06(0.63)$ \\
\hline Ferritin $(\mu \mathrm{g} / \mathrm{l})$ & 106 & $16.8(14.4,19.7)$ & $122(108,137)$ & $0.34(<0.001)$ \\
\hline Total body iron (mg/kg) & 106 & $3.2 \pm 3.8(-10.3-12.4)$ & $8.4 \pm 2.6(1.2-13.1)$ & $0.25(0.01)$ \\
\hline Hepcidin (ng/ml) & 104 & $21.8(18.4,25.8)$ & $98.5(83.1,116)$ & $0.31(0.001)$ \\
\hline $\mathrm{EPO}(\mathrm{mlU} / \mathrm{ml})$ & $n$ & Maternal delivery & Cord blood & $r(P)$ \\
\hline Hemoglobin (g/dl) & 112 & $11.5 \pm 1.6(6.5-17.2)$ & $14.4 \pm 2.6(7.0-20.8)$ & $-0.08(0.40)$ \\
\hline Ferritin $(\mu \mathrm{g} / \mathrm{l})$ & 175 & $21.8(19.3,24.8)$ & $117(104,130)$ & $0.08(0.30)$ \\
\hline $\mathrm{sTfR}(\mathrm{mg} / \mathrm{l})$ & 177 & $5.0(4.6,5.4)$ & $7.6(7.2,8.1)$ & $0.18(0.02)$ \\
\hline Total body iron (mg/kg) & 175 & $4.0 \pm 4.1(-9.1-19.9)$ & $8.3 \pm 3.1(-0.6-17.2)$ & $0.05(0.52)$ \\
\hline
\end{tabular}

EPO, erythropoietin; sTfR, soluble transferrin receptor.

aData are presented as the mean \pm SD (range) for hemoglobin and total body iron; geometric mean ( $95 \%$ Cl) for EPO, ferritin, hepcidin, and sTfR.

lower cord SF $(88.2 \mu \mathrm{g} / \mathrm{l},(95 \%$ CI: 69.4, 113.3), $n=28) \mathrm{com}-$ pared to neonates born to mothers with $\mathrm{SF} \geq 12.0 \mu \mathrm{g} / \mathrm{l}$ at midgestation (26.1 $\pm 3.5 \mathrm{wk}$ gestation) (135.6 $\mu \mathrm{g} / \mathrm{l},(95 \% \mathrm{CI}: 119.1$, $154.5), n=78, P=0.003)$. Furthermore, a significantly higher percentage of neonates with cord SF $<76 \mu \mathrm{g} / \mathrm{l}$ were born to mothers with $\mathrm{SF}<12.0 \mu \mathrm{g} / \mathrm{l}$ compared to neonates born to mothers with $\mathrm{SF} \geq 12.0 \mu \mathrm{g} / \mathrm{l}$ ( 29 vs. $12 \%, P=0.04$ ). Cord hepcidin was significantly positively associated with maternal hepcidin at mid-gestation $\left(R^{2}=0.10, P=0.001, n=104\right)$.

At delivery, cord EPO was also significantly negatively correlated with maternal hemoglobin concentrations at delivery ( $r=-0.19, P=0.01, n=156)$. In contrast to the relationships observed at mid-gestation, no significant associations were observed between cord SF and maternal SF at delivery $(P=$ $0.30)$ or between cord hepcidin and maternal hepcidin at delivery $(P=0.10)$. This may be explained by labor-induced inflammation as we have previously found that ferritin and hepcidin concentrations were affected by the increased maternal inflammation observed at delivery (19).

\section{DISCUSSION}

In this study, anemia was evident in nearly one-quarter (21\%) of healthy term newborns born to pregnant adolescents. At this time, there are no national data to directly compare this prevalence to, as 1- to 2-y olds are the youngest age group monitored for anemia prevalence by the NHANES (20). Neonatal Hb concentrations have recently been compiled in archived records of nonanemic US newborns with minimal hematology-related pathologies $(n=24,416)(21)$. In relation to our data, nonanemic term neonates in our cohort exhibited a $2.7 \mathrm{~g} / \mathrm{dl}$ lower $\mathrm{Hb}$ concentration on average than the national reference data. Direct comparison of these values is challenging because the US reference data were obtained from a mixture of capillary, venous, and arterial blood, and $\mathrm{Hb}$ concentrations are known to vary between these sources (22). To better control for variability due to site of sampling, our data were compared to weighted mean cord $\mathrm{Hb}$ concentrations published in a review of nine studies ( $15.9 \mathrm{~g} / \mathrm{dl}, n=1,538)$ (23). Using this reference value, mean cord $\mathrm{Hb}$ concentrations of neonates in our study remained on average $1.8 \mathrm{~g} / \mathrm{dl}$ lower than expected. AfricanAmerican neonates in this study exhibited significantly lower average $\mathrm{Hb}$ concentrations $(1.3 \mathrm{~g} / \mathrm{dl}, P=0.03)$ in comparison to the mean $\mathrm{Hb}$ observed in the Caucasian neonates studied. The lower $\mathrm{Hb}$ observed among the African-American neonates is consistent with the $0.8 \mathrm{~g} / \mathrm{dl}$ lower $\mathrm{Hb}$ concentration reported in adult African-American women compared to Caucasian women (ages 18-44 y, $n=2,974$ ) (24).

Deficits in $\mathrm{Hb}$ are a late sign of iron insufficiency and the reductions in $\mathrm{Hb}$ concentrations observed in these neonates may be indicative of insufficient iron reserves at birth. In this cohort, fully $25 \%$ of neonates were born with cord SF $<76 \mu \mathrm{g} / \mathrm{l}$, a percentage that was 2.6- and 2.3-times higher than observed among Chinese $(n=3,699)(2)$ and Norwegian neonates $(n=$ 363) (25), respectively $(P<0.001$ for both). The median cord SF in our study $(124.1 \mu \mathrm{g} / \mathrm{l})$ was approximately $27 \%$ lower than median values reported from both China $(170 \mu \mathrm{g} / \mathrm{l})(2)$ and Norway $(169 \mu \mathrm{g} / \mathrm{l})(25)$, and approximately $7.4 \%$ lower than US data reported in term newborns $(134 \mu \mathrm{g} / \mathrm{l}, n=308)(26)$. In addition, the mean cord SF of neonates born to mothers with low iron stores at delivery ( $\mathrm{SF}<12 \mu \mathrm{g} / \mathrm{l}$ ) in our study $(91 \mu \mathrm{g} / \mathrm{l})$ was approximately $43 \%$ lower than the mean value reported in recent neonatal data from Spain $(160 \mu \mathrm{g} / \mathrm{l})(12)$. The combined $\mathrm{Hb}$ and ferritin data in this group of neonates are indicative of insufficient iron stores at birth when compared to other neonatal populations.

In this study, an unexpected inverse relationship was observed between cord $\mathrm{Hb}$ concentrations and SF, which was opposite to the positive association observed among the 


\section{Articles Lee etal.}

pregnant adolescents that gave birth to these newborns (19), and to that reported among pregnant women (27). An inverse correlation between neonatal $\mathrm{Hb}$ and storage iron has previously been reported in term newborns born to diabetic mothers (28) in support of the premise that iron is preferentially utilized for fetal red cell mass over storage iron but few normative data are available regarding these correlations in otherwise healthy term neonates. Low ferritin concentrations in neonates with high $\mathrm{Hb}$ concentrations may reflect a preferential utilization of iron in support of erythropoiesis. However, the mechanisms responsible for higher ferritin concentrations in neonates with low $\mathrm{Hb}$ concentrations are unknown and do not appear to be due to inflammation given the lack of an association between cord SF and markers of inflammation (IL-6 or hepcidin) in this group as a whole. At this time, the physiological mechanism behind this relationship has not been well established and more studies are needed to address this association.

Neonatal iron stores in umbilical cord serum at birth were best predicted by maternal SF concentrations at mid-gestation. A large study $(n=3,247)$ in maternal-neonatal pairs from China found maternal SF at delivery was related to cord blood SF only among women with $\mathrm{SF}<13.6 \mu \mathrm{g} / \mathrm{l}$; no associations between maternal and neonatal SF were evident in women with SF $>13.6 \mu \mathrm{g} / \mathrm{l}$ at delivery (2). We did not identify an inflection point between adolescent SF at delivery and cord blood SF, and no significant differences were noted in mean cord blood SF of neonates as a function of maternal SF $(<12$ or $\geq 12 \mathrm{~g} / \mathrm{l}$ at delivery). Maternal SF concentrations at delivery are affected by acute delivery-associated inflammatory events. In a previous publication of maternal data from this same study cohort (19), concentrations of SF, hepcidin, and IL-6 were significantly higher at delivery compared to values obtained at mid-gestation. Thus, inflammation may confound the utility of ferritin and hepcidin as iron status indicators at delivery.

Early chemical analysis studies found that fetal total body iron content increased rapidly over the last $4 \mathrm{wk}$ of gestation (29). However, of all the iron status indicators measured in our study, only sTfR and EPO exhibited an increase as a function of the GA at birth across $37-42$ wk of gestation. Ferritin concentrations did not significantly increase across the final 3-5 wk of gestation, but remained constant in the face of increased neonatal birth weight and length. This pattern is different from that reported by Siddappa et al. (26) where cord SF increased with GA across a wider range of GA (23-41 wk gestation). Because we are only measuring circulating iron biomarkers at birth, we cannot evaluate possible changes in iron stores in other body tissues and compartments. Currently, there are insufficient data to tell if the patterns observed are unique to neonates born to pregnant adolescents, or if similar patterns are evident across the same time window in newborns born to biologically mature or nonanemic women.

At this time, little is known regarding the magnitude and determinants of the expression of fetal hepcidin. All term neonates in this study had detectable hepcidin at birth and mean concentrations observed were similar to those reported among term neonates using the same hepcidin assay (30). Hepcidin concentrations were higher in newborns born to mothers with longer durations of labor. This is likely due to inflammation as maternal hepcidin was significantly elevated at delivery when compared to mid-gestation (19), and hepcidin was significantly associated with IL- 6 in both the adolescent at delivery and in neonatal cord blood samples. This should be taken into account when considering use of either hepcidin or ferritin as an indicator of iron status in neonates and their mothers at delivery. Similar findings on the impact of iron stores and inflammation on hepcidin concentrations have been recently reported in healthy infants and toddlers ages 0.5-3 y (31).

The iron endowment at birth is critical in ensuring that the neonate maintains sufficient iron stores over early infancy (4-6 $\mathrm{mo}$ ), a time when the regulation of intestinal iron absorption in response to infant iron stores may not be fully developed $(32,33)$. In this group of neonates, maternal ferritin at midgestation was the most significant predictor of neonatal iron stores at birth. This finding has implications for a more rigorous screening for maternal iron status at a time when there is a window of opportunity to augment maternal and possibly fetal iron stores by increasing maternal iron intake through diet or prenatal supplementation.

To our knowledge, our study cohort is the largest of its kind with data on a panel of cord iron and inflammation biomarkers in neonates born to pregnant adolescents. Given the logistical difficulties and challenges in recruiting teen mothers and obtaining longitudinal data across gestation, our study provides unique and important data from this high-risk obstetric population. We acknowledge that there were several limitations in this study. First, the time of cord clamping was unknown; however delayed cord clamping is standard of practice at the clinic. Second, the clinical significance of the findings remains unclear given the small $\mathrm{R}^{2}$ values. Third, generalizability of these findings are limited due to the small sample size and because the study cohort was predominantly African-American reflecting the disproportionately higher adolescent birth rates among non-Hispanic black $(43.9 / 1,000)$ compared to non-Hispanic white teens $(20.5 / 1,000)(14)$.

Ensuring optimal iron stores at birth and across gestation is essential. Moreover, intervening at key windows of gestation may have clinical implications for the growing fetus as animal models have found that the timing of maternal ID plays a key role in fetal brain development (4). Additional studies are needed to identify optimal concentrations of iron status biomarkers at birth that best support subsequent health and development.

\section{METHODS}

Pregnant adolescents $(n=255)$ were recruited from the Rochester Adolescent Maternity Program at The University of Rochester Medical Center in Rochester, NY (2006-2012). Adolescents were: $\leq 18$ y; $\geq$ 12 wk gestation; carrying a singleton, and had no pre-existing medical complications (HIV infection, diabetes, eating disorders, or malabsorption diseases). Informed written consent was obtained from all adolescents. In teens $\leq 14 \mathrm{y}$ of age, both the teen's assent and parental consent were obtained. The study was approved by the Institutional Review Boards of the University of Rochester and Cornell University. 
GA was determined based on self-reported maternal menstrual history. If the maternal self-report and sonogram data differed by more than $10 \mathrm{~d}$, GA was based on the ultrasound data. Infant medical records were reviewed to abstract birth data and to screen for the following adverse birth events or conditions: admission to the Neonatal Intensive Care Unit, sepsis, respiratory distress, hyperbilirubinemia (>12 mg/dl), antibiotic treatment, and TORCH (Toxoplasmosis, Rubella, Cytomegalovirus, Herpes simplex, and HIV) infections. At birth, neonates were classified as small-for-GA if the birth weight was $<10$ th percentile of the growth curves based on 80,000 deliveries in the Finger Lakes Region of NY State (34). Duration of each stage of labor was defined as Stage 1 (time from onset of contractions to full cervical dilation), Stage 2 (time from full dilation to delivery of the baby), and Stage 3 (time elapsed between delivery of the baby to delivery of the placenta) (35).

Umbilical cord blood $(15 \mathrm{ml})$ was obtained at delivery. Cord blood was not obtained in 50 newborns due to study staffing availability at delivery $(n=9)$; delivery at a different hospital $(n=8)$; fetal death in utero $(n=5)$; maternal refusal to allow blood sampling $(n=3)$; and other miscellaneous reasons associated with adverse birth outcomes $(n=25)$. Cord blood hemoglobin $(\mathrm{Hb})$ concentrations were measured at the Strong Memorial Hospital clinical laboratory (CellDyn 4000 hematology analyzer, Abbott diagnostics, Santa Clara, CA) using Clinical Laboratory Improvement Amendments certified methodology. Neonatal anemia was defined using standard criteria as a cord blood $\mathrm{Hb}$ concentration $<13.0 \mathrm{~g} / \mathrm{dl}$ (22). Of the 205 cord blood samples collected, 12 neonates (Neonatal Intensive Care Unit admission, $n=6$; cystic fibrosis, $n=1$; preterm birth, $n=5$ ) were excluded from the final analyses to focus the analyses on iron status of heathy, term neonates. Hemoglobin concentrations were not measured in 65 newborns because the cord blood samples clotted prior to analysis, or staff was not available at the time of blood collection. Thus late in the study additional $\mathrm{Hb}$ data were obtained in the delivery room using a HemoCue $(n=46)$. Of the $128 \mathrm{Hb}$ values, $64 \%(n=82)$ were analyzed at the Strong Memorial Hospital laboratory only, $12 \%(n=15)$ were assessed by HemoCue only, and $24 \%(n=31)$ had $\mathrm{Hb}$ measures analyzed in both the laboratory and by HemoCue. When $\mathrm{Hb}$ data were available by both methods, the values were significantly correlated $(r$ $=0.70, P<0.001)$, yet to a lower degree than the correlations reported by others (36). Therefore, only the laboratory values were utilized in the statistical analyses presented.

Nonfasted maternal blood $(15 \mathrm{ml})$ was collected at mid-gestation (26.1 \pm 3.5 wk gestation, $n=120)$ and at admission into the hospital for delivery $(39.9 \pm 1.2 \mathrm{wk}$ gestation, $n=193)$. SF (ELISA, Ramco Laboratories, Stafford, TX), sTfR (ELISA, Ramco Laboratories), hepcidin (Intrinsic Life Sciences LLC, LaJolla, CA), serum iron (Perkin Elmer AAnalyst 800, Waltham, MA), interleukin-6 (IL-6) (Millipore Magnetic Multiplex, Temecula, CA), C-reactive protein, and EPO (Siemens Immulite 2000 immunoassay system, Erlangen, Germany) were measured in cord and maternal blood. Maternal dietary iron intake was assessed by 24 -h dietary recall, and frequency of prenatal supplement use was self-reported via questionnaire. Details of the methodology used for each assay, maternal iron status, and maternal dietary iron intake have been previously reported (19). At present, there is no definitive cut-off that is indicative of suboptimal cord SF concentrations. In accordance with several studies that related cord SF to neurodevelopmental outcomes (37-39), for data analysis purposes, we used the same criteria of a cord SF concentration $<76 \mu \mathrm{g} / \mathrm{l}$ to define suboptimal SF concentrations at birth.

\section{Statistical Analysis}

The distributions of variables were examined and geometric means (95\% CI) were calculated for the variables with skewed distributions. Differences in group means of normally distributed variables were compared using independent $t$-tests or ANOVA with Tukey HSD for multiple comparisons. Bivariate correlations between indicators were examined with scatter plots, and correlation coefficients were calculated. Linear regression analyses were performed to identify the determinants of each neonatal iron status indicator. Non-normally distributed variables were log-transformed to achieve normality of the residuals. Statistical analyses were conducted using JMP 10.0 (SAS Institute Cary, NC). Statistical significance was determined at $P<0.05$ in all analyses.

\section{ACKNOWLEDGMENTS}

We thank Francoise Vermeylen and Jason Barry in the Cornell Statistical Consulting Unit for assistance with statistical analyses. We are also grateful to Allison McIntyre, Hannah Stillings, Sarah Caveglia, and Lauren Cowen for participant recruitment and data collection.

\section{STATEMENT OF FINANCIAL SUPPORT}

This study was supported by US Department of Agriculture (USDA) 200535200-15218, Washington, DC; USDA 2009-35200-05171, Washington, DC.

Disclosure: Intrinsic LifeSciences LLC (La Jolla, CA) is engaged in the commercial development of the assay described in this manuscript. M.W. is the President and CEO of Intrinsic LifeSciences LLC (La Jolla, CA) and holds a US patent on the hepcidin C-ELISA, and has ownership interests in the company.

\section{REFERENCES}

1. Strauss MB. Anemia of infancy from maternal iron deficiency in pregnancy. J Clin Invest 1933;12:345-53.

2. Shao J, Lou J, Rao R, et al. Maternal serum ferritin concentration is positively associated with newborn iron stores in women with low ferritin status in late pregnancy. J Nutr 2012;142:2004-9.

3. Gambling L, Dunford S, Wallace DI, et al. Iron deficiency during pregnancy affects postnatal blood pressure in the rat. J Physiol 2003;552(Pt 2):603-10.

4. Mihaila C, Schramm J, Strathmann FG, et al. Identifying a window of vulnerability during fetal development in a maternal iron restriction model. PLoS One 2011;6:e17483.

5. Widdowson EM, Spray CM. Chemical development in utero. Arch Dis Child 1951;26:205-14.

6. Spong CY. Defining "term" pregnancy: recommendations from the Defining "Term” Pregnancy Workgroup. JAMA 2013;309:2445-6.

7. Noble KG, Fifer WP, Rauh VA, Nomura Y, Andrews HF. Academic achievement varies with gestational age among children born at term. Pediatrics 2012;130:e257-64.

8. Evans P, Cindrova-Davies T, Muttukrishna S, Burton GJ, Porter J, Jauniaux E. Hepcidin and iron species distribution inside the first-trimester human gestational sac. Mol Hum Reprod 2011;17:227-32.

9. Nemeth E, Ganz T. Regulation of iron metabolism by hepcidin. Annu Rev Nutr 2006;26:323-42.

10. Rehu M, Punnonen K, Ostland V, et al. Maternal serum hepcidin is low at term and independent of cord blood iron status. Eur J Haematol 2010;85:345-52.

11. Young MF, Griffin I, Pressman E, et al. Maternal hepcidin is associated with placental transfer of iron derived from dietary heme and nonheme sources. J Nutr 2012;142:33-9.

12. Garcia-Valdes L, Campoy C, Hayes H, et al. The impact of maternal obesity on iron status, placental transferrin receptor expression and hepcidin expression in human pregnancy. Int J Obes (Lond) 2015;39:571-8.

13. Chen XK, Wen SW, Fleming N, Demissie K, Rhoads GG, Walker M. Teenage pregnancy and adverse birth outcomes: a large population based retrospective cohort study. Int J Epidemiol 2007;36:368-73.

14. Martin JA, Hamilton BE, Osterman MJ, Curtin SC, Mathews TJ. Births: final data for 2012. Natl Vital Stat Rep 2013;62:1-27.

15. Donahue SM, Kleinman KP, Gillman MW, Oken E. Trends in birth weight and gestational length among singleton term births in the United States: 1990-2005. Obstet Gynecol 2010;115(2 Pt 1):357-64.

16. Harville EW, Madkour AS, Xie Y. Predictors of birth weight and gestational age among adolescents. Am J Epidemiol 2012;176:Suppl 7:S150-63.

17. Centers for Disease Control and Prevention. QuickStats: Percentage of small-for-gestational-age births, by race and Hispanic ethnicity--United States, 2005. Morb Mortal Wkly Rep 2008;57:1359.

18. Institute of Medicine (U.S.). Panel on Micronutrients. DRI: Dietary Reference Intakes for Vitamin A, Vitamin K, Arsenic, Boron, Chromium, Copper, Iodine, Iron, Manganese, Molybdenum, Nickel, Silicon, Vanadium, and Zinc. Washington, D.C.: National Academy Press, 2001. pp. 290-393.

19. Lee S, Guillet R, Cooper EM, et al. Maternal inflammation at delivery affects assessment of maternal iron status. J Nutr 2014;144:1524-32. 


\section{Articles $\mid$ tee etal.}

20. Centers for Disease Control and Prevention. Iron Deficiency - United States, 1999 - 2000. Morb Mortal Wkly Rep 2002;51:897-9.

21. Jopling J, Henry E, Wiedmeier SE, Christensen RD. Reference ranges for hematocrit and blood hemoglobin concentration during the neonatal period: data from a multihospital health care system. Pediatrics 2009;123:e333-7.

22. Orkin SH, Fisher DE, Look AT, Lux SE, Ginsburg D, Nathan DG. Nathan and Oski's Hematology of Infancy and Childhood. 7th edn. Philadelphia, PA: Saunders Elsevier, 2009:33-53.

23. Lorenz L, Peter A, Poets CF, Franz AR. A review of cord blood concentrations of iron status parameters to define reference ranges for preterm infants. Neonatology 2013;104:194-202.

24. Johnson-Spear MA, Yip R. Hemoglobin difference between black and white women with comparable iron status: justification for race-specific anemia criteria. Am J Clin Nutr 1994;60:117-21.

25. Hay G, Refsum H, Whitelaw A, Melbye EL, Haug E, Borch-Iohnsen B. Predictors of serum ferritin and serum soluble transferrin receptor in newborns and their associations with iron status during the first $2 \mathrm{y}$ of life. Am J Clin Nutr 2007;86:64-73.

26. Siddappa AM, Rao R, Long JD, Widness JA, Georgieff MK. The assessment of newborn iron stores at birth: a review of the literature and standards for ferritin concentrations. Neonatology 2007;92:73-82.

27. Byg KE, Milman N, Ole Agger A. Erythropoiesis: Correlations Between Iron Status Markers During Normal Pregnancy in Women with and without Iron Supplementation. Hematology 2000;4:529-39.

28. Georgieff MK, Landon MB, Mills MM, et al. Abnormal iron distribution in infants of diabetic mothers: spectrum and maternal antecedents. J Pediatr 1990;117:455-61.

29. Widdowson EM. Trace elements in foetal and early postnatal development. Proc Nutr Soc 1974;33:275-84.
30. Lorenz L, Herbst J, Engel C, et al. Gestational age-specific reference ranges of hepcidin in cord blood. Neonatology 2014;106:133-9.

31. Uijterschout L, Swinkels DW, Domellöf M, et al. Serum hepcidin measured by immunochemical and mass-spectrometric methods and their correlation with iron status indicators in healthy children aged 0.5-3 y. Pediatr Res 2014;76:409-14.

32. Domellöf M, Cohen RJ, Dewey KG, Hernell O, Rivera LL, Lönnerdal B. Iron supplementation of breast-fed Honduran and Swedish infants from 4 to 9 months of age. J Pediatr 2001;138:679-87.

33. Domellöf M, Lönnerdal B, Abrams SA, Hernell O. Iron absorption in breast-fed infants: effects of age, iron status, iron supplements, and complementary foods. Am J Clin Nutr 2002;76:198-204.

34. Strutz KL, Dozier AM, van Wijngaarden E, Glantz JC. Birth outcomes across three rural-urban typologies in the Finger Lakes region of New York. J Rural Health 2012;28:162-73.

35. Martin WL, Hutchon SP. Mechanism and management of normal labour. Curr Obstet Gynaecol 2004;14:301-8.

36. Sanchis-Gomar F, Cortell-Ballester J, Pareja-Galeano H, Banfi G, Lippi G. Hemoglobin point-of-care testing: the HemoCue system. J Lab Autom 2013;18:198-205.

37. Amin SB, Orlando M, Wang H. Latent iron deficiency in utero is associated with abnormal auditory neural myelination in $\geq 35$ weeks gestational age infants. J Pediatr 2013;163:1267-71.

38. Tamura T, Goldenberg RL, Hou J, et al. Cord serum ferritin concentrations and mental and psychomotor development of children at five years of age. J Pediatr 2002;140:165-70.

39. Armony-Sivan R, Eidelman AI, Lanir A, Sredni D, Yehuda S. Iron status and neurobehavioral development of premature infants. J Perinatol 2004;24:757-62. 